\title{
Correction to: Adaptive RBFNN finite-time control of normal forms for underactuated mechanical systems
}

\author{
Jawhar Ghommam • Ahmed Chemori •
} Faiçal Mnif

Published online: 28 December 2017

(C) Springer Science+Business Media B.V., part of Springer Nature 2017

Correction to: Nonlinear Dyn (2017) 90:301-315

https://doi.org/10.1007/s11071-017-3662-3

The list of authors in the original publication was incomplete. The complete list of authors is shown here, including the third author, Faiçal Mnif.

The original article can be found online at https://doi.org/10. 1007/s11071-017-3662-3.

J. Ghommam ( $\varangle)$

CEM-Lab, Department of Electrical Engineering, National Institute of Applied Sciences and Technology, Tunis,

Tunisia

e-mail: jawhar.ghommam@gmail.com

A. Chemori

LIRMM, Université Montpellier 2-CNRS, 161 rue Ada, 34392 Montpellier, France

F. Mnif

Department of Electrical and Computer Engineering, College of Engineering, Sultan Qaboos University, Muscat, Oman 